\title{
The Pricing of Luxury Goods: A BPM Approach
}

\author{
Qiang Du \\ Durham Business School, Durham University \\ Mill Hill Lane, Durham, UK, DH1 3LB \\ Tel: 86-21-6266-522Ｅ-mail: qiang.du@durham.ac.uk
}

\begin{abstract}
This paper discussed how to understand the price of a luxury good from BPM perspective. BPM provides us a comprehensive framework to explain the pricing mechanism of luxury goods. Based on BPM, an index (IVDI) was compiled to probe how much the price of a luxury good relies on the utilitarian reinforcement. IVDI also provides profound implications to marketers when they promote different luxury goods. Different parts of BPM are linked together, as a whole they will influence a customer's entire buying process.
\end{abstract}

Keywords: BPM, Price, Luxury goods, Behavior psychology

\section{Introduction}

My wife is a handbag lover. I noticed that sometimes she is able to buy a bag from a street stall at 10 US dollars however she has to pay more than 1500 US dollars when she decided to choose a new designed LV handbag from a franchised store.

What makes such huge difference behind? Is it quality, brand or both or even something else? One simple answer is: people are able to buy a low end commodity at relatively low cost while they have to pay much higher cost to obtain luxury goods. According to Collins English Dictionary, luxury is explained as "something that is considered an indulgence rather than a necessity". From academic perspective, this explanation is not perfect because it doesn't tell us how to define luxury goods, what a necessity is and what an indulgence is, so that we can not figure out how much we need to pay premium price than a necessity.

The paper tries to explain why luxury goods are able to charge premium price than normal commodities from pricing theory and customer behavior perspective.

\section{Literature Review}

Numerous studies have been conducted on pricing theory in the past, among which many researches emphasized that the microeconomic is the foundation of pricing theory (e.g. Hawkins 1954 and Nagle 1984). Not like Hawkins, Nagle points out that although economics are important base of pricing theories, there are some other subjects are also crucial to the development of pricing theory such as psychology and sociology. The classical microeconomic theory put price as variable in the function of margin, cost and demand. The goal of a pricing strategy is to figure out the point where the overall profit is maximum from marketer's perspective. On the individual customer side, the utility theory in microeconomics provides us a paradigm to explain individual buying behavior based on an equilibrium in which the customer believe the utility of the money he/she has to pay equals to the utility of the goods he/she will get.

Many scholars try to reveal the correlation between quality and price. Most of these researches are based on the assumption that quality is the basis of price or reversely, price is a proxy of quality. Riesz (1980) surmised the major previous researches on quality and price correlation. These researches point out that the customers tend to use price as the quality indictor if they don't have other choices. However Riesz argues that one of the classic researches conducted by McConnell (1967) is not demonstratively strong enough to support the conclusion that there is a solid correlation between price and customer perceptive quality. Some recent studies also give backup to this argument (Eunsang Yoon and Valerie Kijewski, 1997). It is interesting that Bowbrick (2007) argues that there is no relevancy at all between price and quality by criticizing previous studies from research method and argumentation logic.

A few scholars do noticed that besides quality, there are also some other factors largely influence the customer's perception of price and therefore the buying behavior. Monroe (1973) argues that the customer may consider reference price, price ranges and the last purchasing experience when they do the purchasing. Zeithaml (1988) argues that the customers take value into consideration and he points out that extrinsic cues, such as brand name and advertising level, rather than only intrinsic cues which is closely related to good's physical attributes, also play crucial role in customers' 
price perception and buying behavior. Chao and Schor (1998) did an empirical research on women's buying behavior in cosmetic purchasing. They argue that the customers make purchases in order to achieve relative position, namely status, so compared with the implication of social position, the good's physical attributes or quality is not as much important.

Although the researches mentioned above partially explained how customers evaluate the price and the way they make a buying decision, none of these researches provided a comprehensive framework to analyze a customer's buying behavior. Furthermore, most of these researches are weak specially when explain why customers would like to choose a luxury good even its prices may much higher than that of a commodity. Kemp (1998) tried to give us some hints in this field and tells us how to separate the luxuries from necessities through three studies. Frijters (1998)'s finding brought us more about pricing of luxury goods. He argues that the reason why the customers purchase luxury goods is because luxury goods are able to bring customers social status, to keep this status both customers and vendors are willing to maintain a higher price. In general, although luxury industry grew rapidly in the past years worldwide, few researches have done to deeply study how this market operates (Xiao and Nicholson, 2007) and why the luxury goods deviate from normal price-quality perception.

My understanding to the pricing of luxury goods is straightforward. Since the customer is the object who conducts the buying behavior, we should put the customer as our research subject rather than those external factors such as quality or even price. BPM (Behavior Perspective Model, Foxall, 1993, 1998, 2007) is a research framework on customer buying behavior based on economic psychology. Figure one below shows this model.

\section{Insert Figure 1 here}

In some recent literatures, BMP is represented below as Figure 2.

\section{Insert Figure 2 here}

Figure 1 and Figure 2 are the same in general while the only difference is that in figure 2, aversive stimuli is separated into two parts and described as punishment.

\section{Introduction of BPM}

Customer behavior setting refers to the environment in which antecedent events that influence the customer behavior occurred, it facilitates or inhibits the customer's choice. Four key stimuli may operate in it: physical, social, regulatory and temporal.

Learning history is the accumulative experience of a customer in the past which will influence current buying behavior it reflects the buying behavior difference among individuals as well.

Utilitarian and informational Reinforcement are direct satisfaction derived from buying and consuming the goods and indirect feedback on consumer's buying behavior.

Aversive stimuli are the cost of consuming economic goods on both utilitarian and informational punishment. For example, a customer must pay out money or may have to wait in a big queue when make a certain consumption.

\section{BPM and Price}

\subsection{Reinforcement and perceived value}

Reinforcement and punishment play crucial role in shaping a customer's buying behavior through value perception. Utility theory in microeconomics formulates that a customer will make judgment on a good's utility and compare it to the utility of the money, namely the price of this good, he/she has to pay out and if the latter one is bigger than the former one, the customer will feel it is a good deal and therefore make the purchase decision. If we consider utility theory from BPM perspective, we can see that in reality, a customer perceives the value of a good based on both utilitarian reinforcement and informational reinforcement. In other words, from a customer's point of view, the perceived value of a good has two parts, the first part is its usage value, traditionally named as the utility, the second part is its given social status value which is represented by informational reinforcement. The customers also take aversive stimuli into consideration when they evaluate the value of a good. We should understand that the utilitarian and informational reinforcement are not always positive, they can be negative when we call them aversive stimuli or utilitarian/ informational punishment. The perceived value is the total sum of positive reinforcements and potential negative punishments. For example, if a customer in China buys a BMW car, he/she gains high utilitarian reinforcement because of BMW's excellent driving performance, however since most Chinese people regard BMW as new-rich's favorite, the customer may suffer from negative informative punishments from others. So the perceived value of a BMW car based on this customer's point of view is sum of value from utilitarian reinforcement (which is positive + ) and value from informative punishment (which is negative -). See figure 3.

\section{Insert Figure 3 here}

In daily life we can see many types of luxury goods from lady's perfumes to private jet planes. All these luxury goods (actually all commercial goods) share one common feature, that is, usage value which can bring utilitarian 
reinforcement to the customer. Luxurious services, for example, a luxurious tourism service which is not a typical produce good, also caters to a customer's utilitarian needs through consuming tangible products such as delicious foods and intangible services such as SPA. So the utilitarian reinforcement endows the intrinsic value to a good and the study of how utilitarian reinforcement affects the price of luxury goods will bring us profound implications.

To study the relationship between utilitarian reinforcement and selling price of different luxury goods, we need to build an appraisal system and make a virtual product as the benchmark. We quantize the utilitarian reinforcement of our target luxury good and divide it to that of benchmark. Show below as formula 1.

$$
\mathrm{I}_{\mathrm{u}=} \mathrm{U}_{\mathrm{t}} / \mathrm{U}_{\mathrm{b}}
$$

In above formula, $U_{t}$ denotes the quantized utilitarian reinforcement of research target, $U_{b}$ represents the utilitarian reinforcement of benchmark of each product category. $I_{u}$ indicates the intrinsic value degree of research target to the benchmark.

To compare the prices between the target and the benchmark, we use price of the target divided by the price of the benchmark as an index. See formula 2.

$$
\mathrm{P}_{\mathrm{u}}=\mathrm{P}_{\mathrm{t}} / \mathrm{P}_{\mathrm{b}}
$$

In above formula, $\mathrm{P}_{t}$ is the price of research target; $\mathrm{P}_{\mathrm{b}}$ is the price of benchmark of each product category. $\mathrm{P}_{\mathrm{u}}$ tells us the ratio of the price of our research target versus the price of the benchmark.

Since $I_{u}$ indicates the intrinsic value of the research target and $P_{u}$ indicates its price level to that of the target, we can compare $I_{u}$ and $P_{u}$ to check whether intrinsic value of the research target is linear with its price based on virtual product reference frame. Formula 3 below shows the details.

$$
\frac{\mathrm{Iu}}{\mathrm{Pu}}=\frac{\mathrm{Ut} / \mathrm{Ub}}{\mathrm{Pt} / \mathrm{Pb}}=\frac{\mathrm{Ut} \times \mathrm{Pb}}{\mathrm{Ub} \times \mathrm{Pt}}
$$

According to above demonstration, we know that $\mathrm{I}_{\mathrm{u}} / \mathrm{P}_{\mathrm{u}}$ is able to indicate how much the price of our selected research target is based on its intrinsic value namely, utilitarian reinforcement, so here we define $\mathrm{I}_{\mathrm{u}} / \mathrm{P}_{\mathrm{u}}$ as Intrinsic Value Dependency Index (IVDI):

$$
\mathrm{IVDI}=\frac{\mathrm{U} \mathrm{t} \times \mathrm{Pb}}{\mathrm{Ub} \times \mathrm{P}_{\mathrm{t}}}
$$

The first step to calculate IVDI is to construct the benchmark based on abstract specifications from a certain product category. For illustration, I choose lady handbag as an example to show the steps.

The key specifications of a lady handbag are material, design and quality. However, each of these features has different weighting factor, some of the features are basic such as quality and others are value-added selling points such as fashion design. The benchmark product we construct should have most of these key features and normally it is the main stream model or design in the market. LV is a well known luxurious brand of lady handbag, therefore I choose LV as the research target. Below table shows features and weighting factors of a lady handbag as an example.

\section{Insert Table 1 here}

According to above table, $\mathrm{U}_{\mathrm{t}}=93$ and $\mathrm{U}_{\mathrm{b}}=58$, So $\mathrm{I}_{\mathrm{u}}=93 / 58=1.603$.

Now we need to figure out $P_{t}$ and $P_{b}$. Here we use the average price of middle end brands as $P_{b}$ and use average price of all LV serials as $P_{t}$. Based on my previous experience, $P_{b}$ is 1000RMB while $P_{t}$ here if we choose LV, is 8000RMB. So $\mathrm{P}_{\mathrm{u}}$ is 8 and IVDI $=1.603 / 8=0.201$.

Suppose one extreme case in which the research target is the same as the benchmark. In this case, $\mathrm{U}_{t}=\mathrm{U}_{\mathrm{b}} ; \mathrm{P}_{\mathrm{t}}=\mathrm{P}_{\mathrm{b}}$ so IVDI=1, which means 1) utilitarian reinforcement contributes all value to the goods 2) no price surplus for informational reinforcement. However if IVDI is 1 , we can not deduce that the good only has utilitarian reinforcement because if for example, $\mathrm{Ut} / \mathrm{Ub}=\mathrm{Pt} / \mathrm{Pb}=2$, we still can make IVDI $=1$. We only can predict that the price represents merely utilitarian reinforcement, informational reinforcement, if any, is not reflected by the price. When $U_{t} / U_{b}>P_{t} / P_{b}$, then IVDI $>1$, it means the price does not fully reflect the intrinsic value (utilitarian reinforcement); when $U_{t} / U_{b}<P_{t} / P_{b}$; the IVDI will be less than 1 which means the utilitarian reinforcement can not solely support the price, informational reinforcement also, on some extent, contributes to the price. If informational reinforcement supports most of the price, IVDI will be very small, such as above example of LV.

The value of IVDI helps us to identify which category a product belongs to. If IVDI equals to 1, it is a commodity; if $\operatorname{IVDI}<<1$, it is a luxury good. Refer to the figure 4 . 


\section{Insert Figure 4 here}

When IVDI is less than 1 , $I_{u}$ (i.e. $U_{T} / U_{b}$ ) can be small or relatively large. If $I_{u}$ is small, it means most value of the good comes from informational reinforcement, the utility does not play key role in the price setting. Some luxury goods follow this pattern such as handbag, apparel, pens etc. While if $I_{u}$ is relatively large, it indicates that although informational reinforcement still contributes much to the price, the good itself has high utility comes from design, advanced technology or superior processing. Some sophisticated luxury goods like luxurious car, private jet plane or luxurious yacht have high $\mathrm{I}_{\mathrm{u}}$ and small IVDI.

Since utilitarian reinforcement brings a good the intrinsic value, for a luxury good with low IVDI and low $\mathrm{I}_{\mathrm{u}}$, the manufacturers always try to enhance its utility by adding jewels or noble metals. On the opposite, high $\mathrm{I}_{\mathrm{u}}$, therefore strong utilitarian reinforcement, is a big differentiator of those sophisticated luxury goods with low IVDI. Image how many cars are able to speed up to 100KM per hour within 4 seconds while a Lamborghini can do so easily?

Also we can see the difference on luxury goods with different $I_{u}$ from marketing perspective. The marketing communication to luxury goods with low $I_{u}$ always focus on life style or elegance and such intangible concepts, while marketing to luxurious cars which $\mathrm{I}_{\mathrm{u}}$ is relatively high are more focus on uniqueness or state-of-the-art technology.

\subsection{Antecedents and perceived value}

In the BPM, customer behavior setting and learning history are called antecedents because both provide the customer some clues of behavior's performance.

Environment setting plays an important role in a customer's price perception, therefore we can see that all boutiques selling luxury goods from apparel to cars have cozy environment and provide warm one on one service. Also we can observe that luxury good shops always locate in premium areas with decent decoration. All these factors send out a message to the prospective customers that they are able to receive good services, obtain superior goods and get other people's admire. Here decent decoration and distinguished service are physical stimuli and premium location is the social stimuli to the customer. Customer behavior setting changes the customer's value perception and therefore the acceptance of price. However the way customer behavior setting changes customer's value perception is different from that of reinforcements (utilitarian and informational). Utilitarian reinforcement and informational reinforcement bring value to the goods the customer will buy while customer behavior setting brings value to the process of buying. The customers who buy luxury goods not only pay attention to the attributes of goods to be bought they also require an enjoyable buying experience which matches their social status.

Learning history however, not like environment setting, influences customer's perception from outside; it changes customer's mindset from customer's past experience and knowledge. The influence can come from several sources such as previous self buying experience, recommendations from friends, relevant book knowledge, common sense and advertisements. The marketers of luxury goods struggle to influence the customer though all channels mentioned above. So we can understand why they try to make buying experience sweet, care the words of mouth and promote noble advertisements.

Although we can study the price of luxury goods from different perspective, behavior setting, learning history and reinforcements are linked with each other. Behavior setting will change the customer's learning history, using the goods, therefore utilitarian and informational reinforcement also helps to build a customer's learning history. Utilitarian reinforcement of a good, on certain extension, determines how the customer be served and under what type of environment. The experience of buying a car and a handbag is totally different.

\section{Conclusion and discussion}

We discussed how to understand the price of a luxury good from BPM perspective in this paper. BPM provides us a comprehensive framework to explain the pricing mechanism of luxury goods. Based on BPM, an index (IVDI) was compiled to probe how much the price of a luxury good relies on the utilitarian reinforcement. IVDI also provides profound implications to marketers when they promote different luxury goods. Different parts of BPM are linked together, as a whole they will influence a customer's entire buying process.

Not many researches have been done to study the pricing of luxury goods from behavior psychology standpoint. This paper is one of these few attempts. However in this paper I only raised one possible view angle to analyze the pricing mechanism of luxury goods, although IVDI is well defined in the paper it is weak in explaining the real business cases.

Several difficulties need to be solved in the further researches. First, we should figure out how to build a fair benchmark system. In this paper I only gave a very simple example to illustrate how to make a benchmark, however in reality, most cases are much complicated than lady handbag. For instance, if we want to make a benchmark for a mobile phone, how can we set weighting factors? In other words, does a customer care the screen size more than GPS function? So to abstract a virtual benchmark product, we have to analyze the customer's preference to all attributes of a certain product. Second, we need a more clearly quantitative description to the implication of IVDI. In this paper I pointed out that if 
$\mathrm{IVDI}=1$ it means the product is a commodity, if $\mathrm{IVDI}<<1$, the product belongs to luxury goods. This description gives us a picture on quantitative analysis from BMP, however the reference data is still ambiguous, we do not know clearly from the value of IVDI on which point it predicts the feature of a good. Empirical data analysis is expected to be conducted so as to build a full panorama of correction between IVDI and product attributes.

I also think IVDI and $I_{u}$ can be applied to the marketing practice. Since IVDI and $I_{u}$ tell us the degree of how much intrinsic value contributes to the product price, markers are able to compare IVDI and $\mathrm{I}_{\mathrm{u}}$ of products from competitors and change their marketing strategy if necessary.

\section{References}

Angela Chao \& Juliet B. Schor. (1998). Empirical tests of status consumption: Evidence from women's cosmetics. Journal of Economic Psychology, 19, 107-131.

Edward R. Hawkins. (1954). Price Policies and Theory. The Journal of Marketing, Vol. 18, No. 3, pp. 233-240.

Eunsang Yoon \& Valerie Kijewski. (1997). Dynamics of the relationship between product features, quality evaluation, and pricing. Pricing Strategy \& Practice, Vol. 5, No. 2, pp. 45-60.

Gordon R. Foxall. (1993). A Behaviourist Perspective on Purchase and Consumption. European Journal of Marketing, Vol. 27, No. 8, pp. 7-16.

Gordon R. Foxall. (1998). The behavioural perspective model Consensibility and consensuality. European Journal of Marketing, Vol. 33, No. 5/6, 1999, pp. 570-596.

Gordon R. Foxall. (2003). The behavior analysis of consumer choice: An introduction to the special issue. Journal of Economic Psychology, 24 (2003) 581-588.

Kent B. Monroe. (1973). Buyers' Subjective Perceptions of Price. Journal of Marketing Research, Vol. 10, No. 1 (Feb.), pp. 70-80.

Manuscript of paper presented at the 3rd Annual Colloquium of the Academy of Marketing's Brand, Corporate Identity and Reputation Special Interest Group. London, UK. Sept 2007.

McConnell, J. D. (1967). A Behavioral Study of the Development and Persistence of Brand Loyalty for a Consumer Product, Ph.D. dissertation, Stanford University, \#67- 17459.

P. Bowbrick. (2007). Pseudo Research in Marketing: The Case of the Price/Perceived-Quality Relationship. European Journal of Marketing, 14, 8, 466-470.

Paul Frijters. (1998). A model of fashions and status. Economic Modeling, 15, 501-517.

Peter C. Riesz. (1980). A Major Price-Perceived Quality Study Reexamined. Journal of Marketing Research, Vol. 17, No. 2 (May, 1980), pp. 259-262.

Sarah Hong Xiao \& Michael Nicholson. (2007). Durham Business School, UK.

Simon Kemp. (1998). Perceiving luxury and necessity. Journal of Economic Psychology, 19, 591-606.

Thomas Nagle. (1984). Economic Foundations for Pricing. The Journal of Business, Vol. 57, No. 1, Part 2: Pricing Strategy (Jan., 1984), pp. S3-S26.

Valarie A. Zeithaml. (1988). Consumer Perceptions of Price, Quality, and Value: A Means-End Model and Synthesis of Evidence. The Journal of Marketing, Vol. 52, No. 3 (Jul., 1988), pp. 2-22. 
Table 1. Features and weighting factors (example)

\begin{tabular}{|cccc|}
\hline Feature & Weighting Factor & Benchmark Score & LV Score \\
Material & $40 \%$ & 20 & 35 \\
Design & $50 \%$ & 30 & 48 \\
Quality and & $10 \%$ & 8 & 10 \\
Durability & Total & 58 & 93 \\
\hline
\end{tabular}

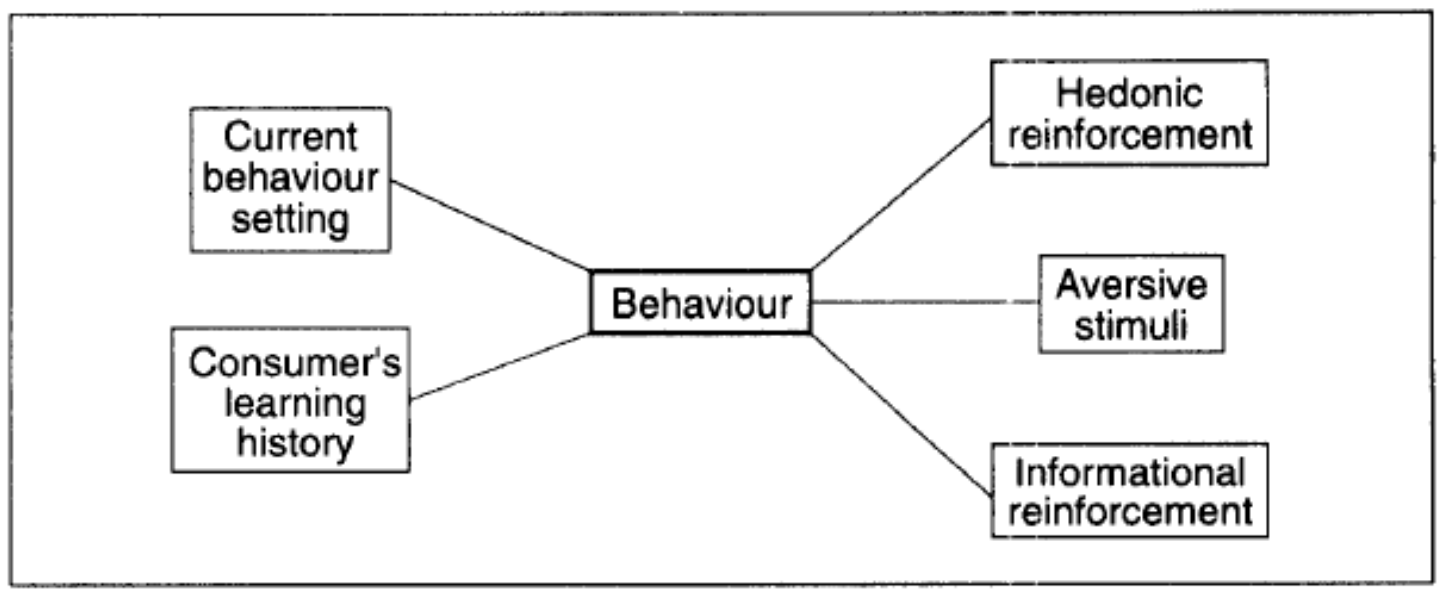

Figure 1. BPM (Foxall, 1993)

\section{The Behavioural Perspective Model}

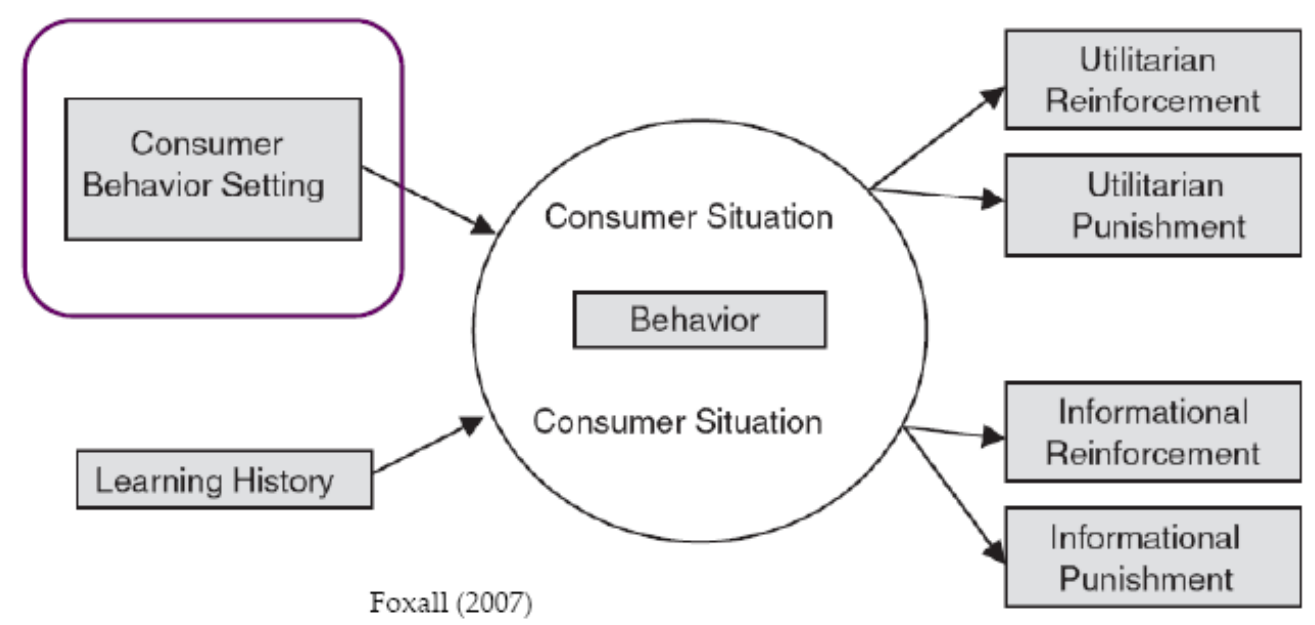

Figure 2. BPM 


\section{The Behavioural Perspective Model}

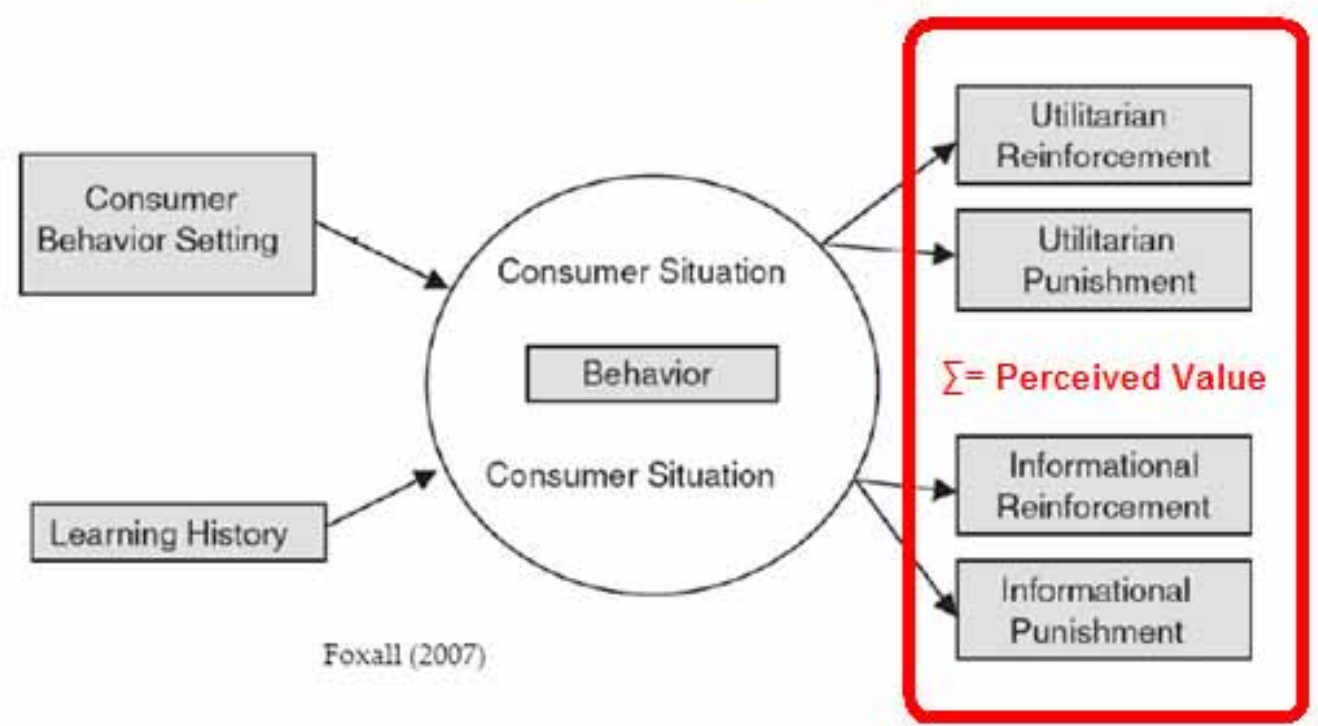

Figure 3. Perceived Value

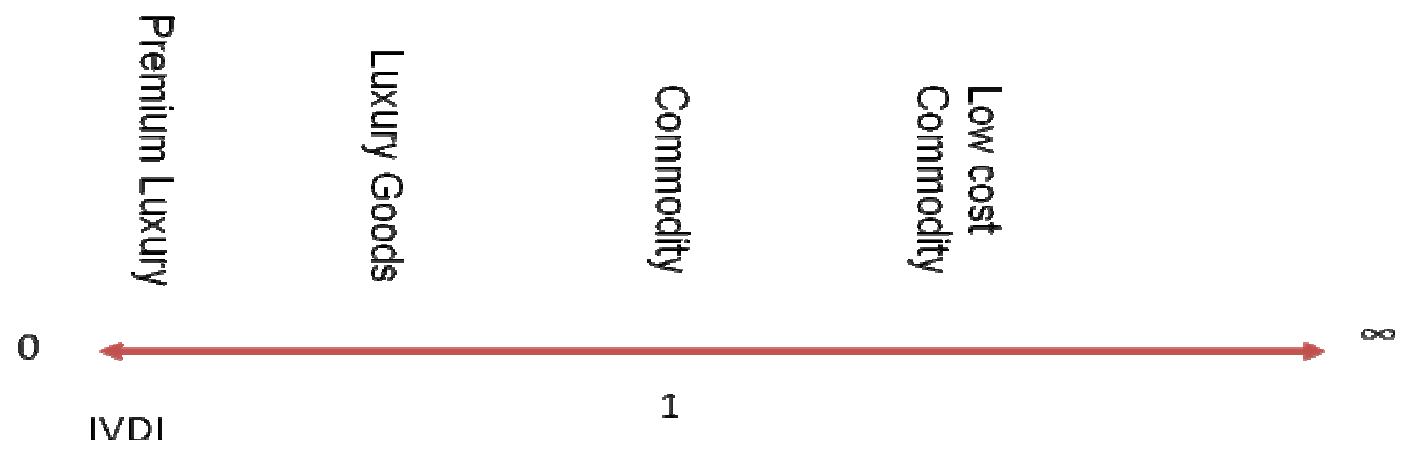

Figure 4. Implication of the value of IVDI 